Technocratic discourse: A primer

Journal of Technical Writing and Communication, 30, (3): 219-247.

Dr. Bernard J. McKenna

School of Communication

Queensland University of Technology

and

Philip Graham

Department of Management

University of Queensland 


\title{
Technocratic discourse: a primer
}

\begin{abstract}
This paper describes the linguistic and semantic features of technocratic discourse using a Systemic Functional Linguistics (SFL) framework. The paper goes further to assert that the fuction of technocratic discourse in public policy is to advocate and promulgate a highly contentious political and economic agenda under the guise of scientific objectivity and political impartiality. We provide strong evidence to support the linguistic description, and the claims of political advocacy, by analysising a 900-word document about globalization produced by the Australian Department of Foreign Affairs and Trade (DFAT).
\end{abstract}




\section{Introduction}

This paper critically analyses the intersection of economic and technical discourses in the genre of technocratic discourse. The function of technical writing and communication, and indeed language in general, is to 'organize reality' $[1,169]$. This is especially the case for technical writing in the physical sciences which organises reality according to relatively strict traditions $[2,3]$. The tradition of logical positivism, with its emphasis on logical relations between words and what they represent [3], is responsible, in large part, for the rigorous way in which scientists describe the physical world. As Halliday and Martin [1] show, scientific language has a clearly recognisable grammar, form, and function appropriate to its use in the physical sciences [1, 38]. We argue that a specific form of technocratic discourse, the discourse of "globalisation", normatises neoclassical economic ideology in the process of advancing what appears to be technical solutions to currently perceived problems.

Scientific discourse, at least its lexico-grammatical guise, has steadily crept into widespread use, not only into the social sciences, but also into the languages of business, government, and international policy centres. While scientific discourse may be quite appropriate to some areas of these fields, we argue here that technocrats use the apparent objectivity of scientific discourse for mostly manipulative purposes by presenting 'highly contentious' statements as 'uncontentious'-often, indeed, as fact $[1,197]$. Technocratic discourse has become a recognisable feature of public policy, business, and the social sciences in the current milieu of economic and social upheaval [4; 5, chapt. 1]. In this paper, we focus most specifically on the discourse of 'globalisation', which is widely construed as the rationale for sweeping economic reforms throughout the developed and developing worlds [4] .

"Globalisation" is an abstraction of the highest order: it has no independent physical existence. But policy makers, from the relatively insignificant Queensland State Government [6] and the Australian Federal Government's Department of Foreign Affairs and Trade [DFAT] [7], to the largest international organisations, such as the Organisation for Economic Cooperation and Development (OECD) [8] , the International Monetary Fund [IMF] (1998)[9], and the World Trade Organisation [WTO] (1999) [10] all claim "globalisation" as their rationale for sweeping reforms. 
The arguments underpinning the discourse of "globalisation", at least as it is presented by today's technocrats, are far less rational and objective than they appear to be at first glance. This is a function of the genre we are describing here. We argue that technocratic discourse makes use of abstractions such as "globalisation", "efficiency", "the national interest", and so on, in much the same way that the great religions have named their gods as the ultimate arbiter of individual fate, past and future fortunes, and, indeed, the well-being of entire nations. Naturally, we find the technocratic use of language disturbing and potentially damaging.

Technocratic language draws interdiscursively from scientific discourse, and from technological discourse. It also draws historically from the lexico-grammars of managerialism, the military, and of religion, in particular, that of the scholastics [11]. Technocratic discourse appears to be objective and rational because of its pseudoscientific appearance. But it is precisely the opposite in most cases. Such a discourse, then, deserves considerable attention because of its potentially profound impact and widespread use. Today, technocratic discourse suffuses the policy statements of what were formerly recognisable as left- and right-wing parties, but which are recognisable as such no longer, precisely because of their technocratic language. Its use thereby has eliminated dialectical political encounters, and, consequently, the possibility for public debate on important matters of social policy $[12 ; 13,10 ; 5]$

\section{Definitions}

We use the term technocracy to indicate that the power of governing is shared in the modern state, by parliament, a bureaucracy, and a technocracy [14] . The technocracy comprises economic planners, strategic thinkers, and natural and social scientific experts. By technocrats, we mean people who transform 'discourses of expert knowledge into discourses of social policy' 15, 58]. They are 'makers of politics and purveyors of mass information' $[16,28]$, the 'catalysts of the Third Industrial Revolution and the ones responsible for keeping the high-tech economy running' [17, 175].

\section{Theoretical orientation}

This paper adopts a critical approach using systemic functional linguistics [SFL] as the means of analysis. Because SFL terminology is not widely recognised, we use common Latinate grammar terms to explain SFL terminology where necessary. Our critical perspective has its origin in the Frankfurt School, especially in the writing of 
Adorno [18] and Marcuse [16] . From the Frankfurt School perspective, social relations are increasingly objectified as more and more intimate aspects of social life become commodities $[4,19]$. This critical perspective separates our particular concern with technocracy away from the dehumanising features of a scientifically controlled society - a concern in its own right - towards a concern with the implications of a totalising hegemony ${ }^{1}$ that strategically incorporates technocratic discourse and uses pseudoscientific language and rationality to promote inequitable and predatory social policies that favour corporatist practices.

Technocratic discourse is most clearly characterised by the way it represents itself: although it has a clearly hegemonic function, it consciously presents itself as " above the fray", as a supplier of "facts", neutral and objective, free of all interests and values except truth, which all parties must take into account in deciding policy' [15, 70]. It does so by adopting a form of scientificity that is a mere parody of science, and by representing its epistemic claims - often tacit - as objective knowledge [15, 69]. Even though technocratic

${ }^{1}$ Hegemony is best understood in terms of the options to coerce (or be coerced) or to seek consent (or give consent). Foucault and Gramsci agree that 'the operations of power and their success depend on consent from below' [49, 29]. Although Gramsci's personal circumstances might have suggested otherwise, he had argued prior to Foucault that a characteristic of the modern state is that coercion is less necessary and effective than obtaining consent. Coercion could best be described as a political act where compulsion 'is regularized, generalized, concentrated, and rendered explicit' [50, 90]. By contrast, Gramsci's notion of consent, implies the need to 'transform' oneself, 'for in "consenting", the individual enters into a relationship and by participating in such a relationship, social reality becomes something other than what it would have been, had the act of consent not occurred' [50 pp. 124 - 125]. This really is the foundation of poststructural notions of subjectivity. Bourdieu [51] reached a similar conclusion. According to him, all symbolic domination presupposes that those who submit engage in a form of complicity 'which is neither passive submission to external constraint nor a free adherence to values' (pp. 50 51). In short, hegemony is that which transcends ideology insofar as it remains largely invisible by dint of its dominance. 
deliberations usually end in recommended social policies, and, ultimately, in implementing those policies, it eschews any notion that such policies operationalise value systems that impact differentially on people thereby producing or maintaining structural inequality. However, technocratic discourses have quite well-defined value systems, implicit ones, that serve the dominant economic interests of the corporatist and "managerial" classes [11].

Technocratic discourse 'ventriloquates' scientific discourse $[15,77]$ to claim rational objectivity and to promote action supposedly based on reason and fact: 'economists, political scientists and sociologists in particular have attempted to imitate scientific analysis through the accumulation of circumstantial evidence, but, above all, through their parodies of the worst of the scientific dialects' [12, 49]. However, although it adopts positivist science's claims to identify "true" causes, technocratic discourse 'begins with an action it covertly wants to recommend as policy, and then cites "research evidence" and "studies" which show that this action is a necessary cause of something else that is positively valued by those to be convinced' $[15,71]$. Because technocratic discourse can prescribe and proscribe action according to "objective" knowledge and principles, and moreso because it is written mostly by a small number of people representating the interests of multinational enterprises and operationalised by supranational legislative bodies, such as the WTO [20], opposition to technocratic language becomes difficult. However, when looked at more closely, the discourse is characterised by 'self-validating hypotheses which, incessantly and monopolistically repeated, become hypnotic definitions or dictations' $[16,28]$. For example, the claim is often made 'that democracy issued from the womb of the marketplace': that is, that free speech and free elections are a function of free trade, a clearly contestable assertion [12, 46; cf. 21].

The language of technocracy is a closed discourse that treats opposition as incorrect propaganda $[16,80]$. Because "incorrect" oppositional discourses are often cast as naïve "common sense", they are pervasively denigrated by technocrats, and are tacitly supposed to defer to the more intelligent scientific knowledge generated by the technical elite $[15,71]$. In this way, the pseudo-scientific language of technocracy legitimises its claims to power in matters that are uniquely social in nature, simultaneously silencing "common-sense" opposition by their claims to expertise. 
To demonstrate the structure and function of technocratic discourse, we identify and elaborate its definitive features, using technocratic descriptions of "globalisation" to exemplify our arguments. First, we show the circular form of argument which is characteristic of the discourse. We then highlight the key feature of its lexico-grammar. Following this, we show how these features combine to make nonsensical statements that form the basis of governance-by-obfuscation.

\section{The circularity of globalising discourses: A sidestep into the "misty realms of religion"}

The term globalisation clearly has circular allusions, and the technocratic language that describes globalisation makes good use of these allusionary connotations. Being supranationally produced, technocratic language about globalisation generally seeks to show why national governments ought to cede regulatory responsibility to supranational agencies [22]. The discourse of globalisation transcends most previous forms of technocratic discourse insofar as its overt quasi-religious aspects. It even has its own 'Holy Trinity' [23, 144-47]: information technology, free trade, and the financial sector.

Supranational legislative bodies have, for some time, called themselves 'the international community' [24]. According to its members, the international community is very real: 'The international community does exist. It has an address. It has achievements to its credit' $[24,15]$. And indeed the international community shows all the characteristics of a community, which, by our definition, is always a discourse community [25] . Like any other community, the "international" community can be identified by the way it describes the world and its interactions, because '[e]ach community, each discourse tradition, has its own canons of intertextuality ${ }^{2}$, its own principles and customs regarding which texts are most relevant to the interpretation of any one text' $[15,41]$. Discourse analysis examines how language is used to construct things in the natural or social domains by their 'explicit descriptions as participants, processes, relations and circumstances standing in particular semantic relations to one another'; how the discourse community orients itself attitudinally to others, and to the presentational content of its own discourse; and studies the "construction of relations between elements of the

\footnotetext{
${ }^{2}$ Lemke [15, 22] means Bakhtin's [47] definition of the word 'intertextuality': That is, the spectrum of texts from which a discourse community typically chooses in interpreting and describing its world.
} 
discourse itself' $[15,41]$. A corollary to this is that, within a recognisable discourse community, 'thematic patterns ... recur from text to text in slightly different wordings, but [are] recognisably the same, and can be mapped onto a generic semantic pattern that is the same for all' texts about a particular theme [15, 42]. A clearly recognisable thematic pattern, or intertextual thematic formation (ITF), pervades the international policy literature on globalisation. It provides 'organisational coherence' for the discourse of globalisation. The globalising ITF looks like this:

Communication Technologies revolutionise the way Businesses operate because they facilitate Global Trade (or International Trade, International Business Activity, or Global Markets). Financial Sector (also called the Services Sector) Growth, which is integral to Economic Growth, depends on Free Trade (or Open Markets, Trade Liberalisation, or A Liberal Trading Environment). Free Trade is achieved through Deregulation (or Reform). Free Trade creates jobs, freedom, and prosperity and thus is good. Financial Sector growth is facilitated and accelerated by improved Communication Technologies (sometimes called The Communications Revolution). Because communication technologies are revolutionising Global Trade, and because Free Trade is desirable and beneficial, Globalisation, which is characterised and facilitated by Free Trade, Communication Technology, and Deregulation, is both inevitable and desirable. Therefore national regulatory regimes are anachronistic and must be reformed or removed.

The circularity of causal relations and definitions in this ITF, which provides organisational coherence for globalising discourse, allows the technocratic author to enter the discourse at any point, to begin with any element, and promote the virtues and, indeed, the inevitability of globalisation. The causal circularity takes the form of: [1] information technology facilitates global free trade, or globalisation [2] which in turn promotes economic growth in the financial sector, [3] which in turn requires deregulation, [4] which in turn promotes the more fruitful use of information technology, and so we return to $[1]$.

The following examples show how this this self-valorising ITF might appear (main participants from the ITF are underlined):

Communications technology sets this era of globalisation apart from any other. The internet, mobile phones and satellite networks have shrunk space and time", the [United Nations] report says.

Worldwide, the report values e-commerce at $\$ 2.6 \mathrm{bn}$ in 1996, and forecasts that this will rise to $\$ 300$ bn by 2002 - transforming the way business is done around the world. [52]

Globalization-the international integration of goods, technology, labor, and capital-is everywhere to be seen. In any large city in any country, Japanese cars ply the streets, a telephone call can arrange the purchase of equities from a stock exchange half a world away, local businesses could not function without U.S. computers, and foreign nationals have taken over large segments of service industries. Over the past twenty years, foreign trade and the cross-border movement of technology, labor, and capital have been massive and irresistible. $[26,1]$ 
Social and business interactions can be now conducted entirely in a virtual world with the aid of communication and information technologies. The widespread availability of these new technologies and the services they enable has the potential to change forever the way Queenslanders work and play, and the way business is conducted. [27, 1].

The Internet and other information and communications technologies are changing the way we work, learn, communicate with each other, and do business. These technologies are shaping our economy and our society in the same way that the steam engine and electricity defined the Industrial Age. [28]

The realisation of a global information infrastructure and society can be facilitated by explicit and updated domestic and international "rules of the game" based on market competition. Separation of operational and regulatory activities has taken place satisfactorily in most countries and should be continued. The focus of the debate is now turning to new principles that might be required to advance Gll and $\mathrm{GIS}^{3}$. The principles should be flexible, acknowledge the rapid evolution of the GII, GIS and globalisation that seems to be partly driven by economies and corporations becoming more competitive, trade barriers being removed, global operations becoming more feasible, transnational alliances developing, and new communications networks being deployed. [29, 5]

Increased trade may contribute to innovation and the spread of technology, and thus indirectly affect wages.

One potential channel through which technology flows from country to country is the transfer of technology by multinational firms from the parent to its affiliates. Higher foreign investment in a particular industry is usually associated with higher wages in that industry. $[26,15)$

And so it goes, around and around, in an impenetrable circle of reasoning and causality $(A$ causes $B$ causes $C$ causes $D$ causes $A$, etc). Note that the above selections all start with the different elements mentioned in the organisational ITF above. These are, in order:

Communications technology ... ; Globalization ...; Social and business interactions ...;

The realisation of a global information infrastructure ...; Increased trade. Furthermore;

all the authors relate each factor identified in the ITF to all the others as a cause. Thus, these elements are related neither hyponymously [superordinately] nor (co-)

meronymously [constitutively] with each other (see below). Thus they are construed precisely as a Holy Trinity, a three-in-one God, an all-powerful panoply of absolute abstractions, each as powerful as the other, insofar as each is prima causa for the others, but incomplete in themselves: free trade, financial markets, and information technologies. Together, they are globalisation, they also cause globalisation, and they cause each other, at least according to the technocratic authors. Although we could say much more about the highly contestable assumptions underpinning the above statements, time and space do not permit us to do so.

${ }^{3}$ GII: Global Information Infrastructure; GIS: Global Information Society. 
Having shown the broader discursive features of technocratic discourse, we now provide a grammatical and linguistic characterisation of it. Essentially, five features characterise technocratic discourse: four of these are lexico-grammatical and one is semantic. The predominant lexico-grammatical feature in technocratic discourse is the extensive and elaborate use of the nominal and the nominal group. These are used primarily to taxonomise and define. A second feature is the repetition of familiar words (usually a nominal or nominal group) which are almost always highly abstract and heavily condensed. We call this repetitive use of familiar words "mantras" to denote their hypnotic effect .

Two other lexico-grammatical features we identify here concern use of the verb. The third feature of technocratic discourse is that verb use is very limited [1] . The fourth is the relative absence of human agency. At a semantic level, as we have shown above, technocratic discourse is circular, often impenetrably so. In the next section, we explain the four lexico-grammatical features, providing examples from technocratic text about globalisation.

\section{Technocratic use of the nominal and the nominal group}

An important and definitive feature of technocratic discourse is the linguistic functioning of its nouns and nominal groups, particularly its nominalisations [cf. 18, 6-10; 13, 10; 15, $59-66 ; 16,79-83 ; 12,64)$. One of the important functions of nominals and nominal groups is to classify objects and things (Participants in SFL), including abstract things. One important form of the nominal in technocratic discourse is the nominalisation. This allows processes (the action contained in a verb) to be construed as nouns. Thus, oxidise (a process or verb) becomes the nominalisation, oxidation. However, linguistic condensation can be used much more powerfully than this. In the following example, the nominal group, this theoretical expectation, in the second paragraph carries all the information in the preceding 88 word paragraph.

During the sudden collapse of a star under its own gravitational pressure, energy must be released as the mass of the star collapses inward. One can calculate that during this process, which lasts only a few seconds, the total energy released is about $10^{20}$ times as much energy as is released by the sun during those same few seconds. Almost all of this energy is released in the form of neutrinos, because they are the only objects that can permeate the hot, dense environs of the collapsing star.

Never before had [this theoretical expectation] been verified but in ten seconds or so during which the two detectors on earth signaled nineteen neutrino events, supernova theory advanced from pure speculation to empirically tested wisdom. [30, 210]. 
This highlights an important feature of nominalisations: they shift clauses to a lower rank order in the grammar, that is, to the level of a word rather than at the higher order of clause $[1,39]$. We can see that all the information in the first 88-word, 3 -sentence paragraph, which describes an extraordinary complex of processes, participants, and circumstances, is collapsed into a three-word nominal group: this theoretical expectation.

But technocratic texts are rarely so courteous to the reader. Rather than making the meaning of the nominal explicit by relating it to some preceding content, they generally present nominals as self-contained, self-evident things. In other words, technocracy uses nominals to hide semantic relations without ever making their content explicit. As a result, technocratic propositions become less negotiable or contestable because 'you can argue with a clause but you can't argue with a nominal group' [1, 39]. In other words, technocratic nominalisations close off debate by eliminating, or at least presuming, causal and relational processes that would be evident in a clause. Thus, in technocratic discourse, the nominal 'becomes a declaration to be accepted - it repels demonstration, qualification, negation of its codified and declared meaning' $[16,79]$.

Nominal prominence characterises science writing [1]. Nominals and nominal groups serve three important functions: to taxonomise, to convert processes into static events through nominalisation, and to define. We will describe these briefly below.

\section{$\underline{\text { Nominal as Taxonomic }}$}

An important function of the nominal, or nominal group, is to taxonomise the phenomena we encounter. In science, vernacular taxonomies are replaced by scientific taxonomies that allow items to be placed into, for example, division, (sub)class, order, family, genus, species, variety, and so on. Gardeners encounter this all the time: for example, the common name for the tree, Broad Leafed Paperbark, is converted into its botanical name, Melaleuca quinquenervia. In doing this, science takes one step back from the world of ordinary people to talk in an unfamiliar language. But the point of this is not deliberate obscurantism or exclusivism; rather, it is a device that allows the scientist or technician to render the phenomenon in a way that allows it to be analysed according to a set of established scientific principles and taxonomic relations [31].

Thus, for example, when an engineer deals with a waste management problem, the vernacular term, cleaners, is reconstrued as acids and alkalis. [31, 197]. These 
reconstruals from the vernacular into the scientific allow the engineer to apply scientific knowledge which is already organised into taxonomies under categories of acid and alkalis, among other things, each with definable and predictable characteristics. Given that scientists can predict the behaviour of acids and alkalis, they are able to make suggestions for appropriate disposal of different types of products. But when the technical rationality of waste management is transposed into social policy, the effect is frequently to dehumanise the social world:

\begin{abstract}
When Maggie X died, the [aged care] home [Morpeth Castle, Northumbria, UK] decided that her savings of $£ 450$ was insufficient to pay for the funeral and asked the council to pay. It refused and the owner of the home appealed to the Local Ombudsman. In his comments to the latter, the council Chief Executive, wrote that 'without wishing to appear insensitive, one could argue that from a commercial viewpoint residents of a home are its income producing raw material. Ergo, from a purely commercial view, deceased residents may then be regarded as being the waste produced by their business'. Since, he continued, the resident's body was 'controlled waste likely to cause pollution of the environment or harm to human health' the home had, under the definition of controlled waste as defined by the Environmental Protection Act, 'a specific duty' to dispose of the remains. Disposal, under the definitions of the Act, was 'a business cost'.[32].
\end{abstract}

Here we see the potentially dehumanising implications of mixing technical, bureaucratic, and managerialist language. In the above passage, deceased humans are construed as "controlled waste", as merely economic and logistical problems to be dealt with according to "the Act". Humane and ethical considerations are banished, and the treatment of "controlled waste", as defined by "the Act", becomes the definitive prescription for action. All this is premised on the basis of false objectivity, which really just hides vulgar budgetary considerations.

Experts in other technical areas of the social sciences, such as economics and management, categorise observable phenomena using specialised lexes. This, in itself, is not any more inappropriate or undesirable than the scientist or the engineer doing so. However, what often goes unacknowledged is that, in the social sciences, the categorisations are far more contestable, flexible, and far more prone to value judgments by those who taxonomise social phenomena. That is, the flexibility of social scientific taxonomies (eg, class, religion, gender) arises from the ideological context and underpinnings of those who are invested with the power to classify and describe humans and their activities.

Another difference between social science and the "natural" sciences is that, in the natural sciences, the relationship between the various phenomena is generally describable 
and predictable because they are most usually empirically established over long periods of time. ${ }^{4}$ Thus, if in organic chemistry, ionic bonds are formed by the transfer of one or more valence electrons from one atom to another, then we know that an electropositive sodium atom will always link up with an electronegative to form sodium chloride, or salt.

Notwithstanding that the entire edifice of chemistry rests upon the contrivance and mutual agreement of chemical scientists over several hundred years, the internal logic provides an effective means of explaining very specific and naturally occurring phenomena, precisely because they are replicable and predictable. Not so with economics, for example. Without wishing to begin an epistemological debate, simply let us note that neoclassical economics adopts, sheds, reconstructs, and simultaneously uses multiple paradigms of understanding in realms of analysis such as monetary policy, fiscal policy, external policy; and in theories such as the $\mathrm{J}$-curve, theories of comparative and absolute advantage, and so on. Yet, with its theoretical and terminological arsenal, the "new" economics still seems to have a very poor predictive or descriptive capacity. In fact, most economic predictions are wrong $[33,77-81]$.

Ordinal divisions also occur in the process of classification. Superordinate taxonomies ‘build up around the principle of subclassification' $[34,295)$. Superordination incorporates hyponymy, or class stratification [35, 332; 34, 288 -301). Classification of the parts of the whole (composition or constitution) also occur as meronymy [35, 332, $341 ; 34,303$ - 306). Both hyponymy and meronymy are forms of synonomy, although the distinction between these two forms is not always clear [35, 332]. The organisation of a text's taxonomy is not always explicit, but can be inferred from the grammar: for example, hyponymy takes the form $A$ is a kind of $B$ [a rose is a kind of flower], and meronymy takes the form $A$ is part of $B$; or $A, B$, and $C$ are the composite parts of $D$ [Cambodia is a part of South-East Asia; or arms, legs, and seat form parts of a chair].

To return, then, to the notion of the taxonomic function of the nominal. Fundamentally, the "possibility of ordering the things of the experiential world in some field-specific way presupposes both observing and naming relevant phenomena' $[1,143)$.

\footnotetext{
${ }^{4}$ We do not, of course, include new fields such as particle theory, some fields of theoretical astronomy, genetics, and so on.
} 
From this perspective, the phenomena of such areas as economic policy [eg, labour costs; factor price equilibrium] and social policy [eg, health initiatives; emerging technologies] that are named by technocrats are clearly not objectively determined phenomenon that transcend ideology nor even the most basic of assumptions. Indeed, the opposite is most often true $[15,59-66]$. In many cases, such as globalisation, the phenomena are not observable at all. Indeed, their very existence may be a matter for debate.

A result of this is that the attributions ascribed to social categories will often tautologically determine the characteristics of the items placed in that category [All X's have Y characteristics; therefore all Y's are X's]. Finally, just as in an engineers' report, the phenomena discussed in such policy statements are eventually reconstrued back to their everyday, vernacular form in order to suggest a certain order, a certain form of activity, carried linguistically through the process, or verb [31, 209].

\section{$\underline{\text { Nominal as Definition }}$}

The most familiar and frequent linguistic method used to define something is an identifying relational clause which has the structure, Token - Relational Process - Value: for example The biome <Token> is <Relational Process> the living part of the ecosystem $<$ Value $>[1,149]$. This might be understood more easily in latinate grammar terms as the subject is equated with the complement through the use of (usually) the verb to be. One way to identify a phenomenon is by specifying its form: for example,

The record of the electrical activity generated by the cardiac muscle during depolarization is called an electrocardiogram (or ECG).

Another way is to specify how the nominal is valued

Environmental sustainability $<$ token $>$ [offers] $<$ relational process $>$ one of the best examples of the divergent implications of realising (or not) global frameworks conducive to socio-technical transformation <value $>$. [36, 27]

This sentence makes use of all the characteristic features of technocratic discourse, including something we call process metaphor. Process metaphor changes the function of the verb, but it does so only inside the functional grammar of the process, or verb, categories (see below). In this sense, it is similar to grammatical metaphor, in which a word, or a group of words, changes its grammatical function. Globalisation is a good example of how grammatical metaphor works. Indeed, it is informative to note how the grammatical metaphor of globalisation goes full circle: globe (nominal/noun); global 
(epithet/adjective); globalise (process/verb) globalisation (nominalisation/noun). In the Miller et. al. example above, a material process, offers, functions like an identifyingintensive relational process, normally realised as a form of the verb to be. The author(s) say that '[e]nvironmental sustainability offers one of the best examples ...' . But they are saying that environmental sustainability is one of the best examples. A simple test shows that this is the case. Reasonable substitutes for offers in this sentence do not include proposes, proffers, and so on, which would normally be thought of as synonyms for offers. But offers can easily be replaced by forms of the verb to be, including is, will be, will have been.

Although the identifying-intensive process is usually realised through the verb to be [X is $\mathrm{Y}]$, it may be realised through other process words such as equals, adds up to, makes, comes out at, signifies, means, defines, spells, indicates, expresses, suggests, offers, acts as, symbolises, plays [a role], represents, stands for, refers to, exemplifies. Other than token/value relationships, these elaborations can take the form of embedded clauses and nominal groups. Because technocratic definitions are more ideologically and functionally flexible than those in the "natural" sciences, logical and definitive idiosyncrasies arise within the discourse. For instance, in the natural sciences, we can say that a human <token> is <process> a mammal <value>, but not the reverse: a mammal is a human. However, in technocratic discourse, the identifying-intensive relation can often travel in both directions precisely because of the abstract objects in the discourse. For example, globalisation <token> is <process> the driving force of international trade <value> can quite easily be reversed around the process, to mean something similar - the driving force of international trade is globalisation - merely by swapping token for value, something which is not possible in more concrete, less abstract agentless/passive clauses with the same Tok$^{\wedge}$ Val structure $[35,128]$. The rigidity and abstraction of this example appears as even more striking when one considers that all the elements can be shifted around the central process (is) without regard to logical relations whatsoever:

the driving force of international trade is globalisation globalisation is the driving force of international trade the driving force of globalisation is international trade international trade is the driving force of globalisation 
The very fact that these discourse elements can be related without seeming immediately nonsensical draws attention to the possibility that no logical relation exists between them at all, even though the $\mathrm{Tok}^{\wedge} \mathrm{Val}$ relation is performing an implicitly taxonomic, as well as a defining, function.

\section{Mantric Words}

Technocratic discourse uses mantric nostrums, 'abstract notions that obscure real events', and these are used over and over in public discourse [12, 64]. As they are used more and more, they tend to become meaningless. However, in technocratic discourse, such mantras play a vital role because, by infusing the condensed words or phrases throughout everyday language, the rationality of a particular type of political-economic system (in this instance, neo-classical economics and neoliberal politics) is naturalised by repetition. Technocratic mantras juxtapose and relate apparently interchangeable terms like enterprise, efficiency, globalisation, productivity, international competitiveness, trade liberalisation, the information economy, technology, and so on [5, chapt. 2]. For example, an embedded clause in Sentence 45 of the DFAT document says that trade liberalisation and an open economy contribute significantly to economic growth and job creation. Such juxtapositions allow technocratic authors "to tailor the apparent scientific "facts" to the needs of its policy arguments' $[15,75]$. As a result, they allow meaning to be abridged and stripped of its political and ideological connotations [16, 68]. Indeed, in today's technocratic political environment, 'language attached to power is designed to prevent communication' $[12,57]$.

Technocratic condensations are rendered, by repetition, into culturally normative, socially consumed and fetishised mantras that are also often juxtaposed to specific others, like, for instance, the 'holy trinity' that accompanies "globalisation" in public policy (see above). These are, sometimes co-meronymously, sometimes co-hyponymously related to globalisation and are themselves condensations that draw on neo-classical assumptions. By making the relationship between globalisation, trade liberalisation, financial markets, and communication technology familiar and simplistic, the words and phrases become "understandable", "accessible", familiar, and, consequently, even desirable concepts for the public at large:

The fact that a specific noun is almost always coupled with the same "explicatory" adjectives and attributes makes the sentence into a hypnotic formula which, endlessly repeated, fixes the meaning in a recipient's mind. He [sic] does not think of essentially 
different (and possibly true) explications of the noun[s]. ... It is a well-known technique of the advertising industry where it is methodically used for "establishing an image" which sticks to the mind and to the product [16, 81-82].

Technocratic discourse, then, may be viewed as the slogans and "jingles" for technocratic policy statements. Slogans and jingles gain their purchase upon the social consciousness through repetition; and through repetition they are publicly reinforced, rendered recognisable and, thus, "sold" and consumed. As with musical jingles for consumer goods, the familiarity of technocratic discursive forms 'becomes a surrogate for the quality ascribed to it' $[37,26)$. In other words, technocratic discourse becomes a "value" in itself, and command of the discourse and its official conduits becomes synonymous with expertise and power [4].

\section{Limited role of the process / verb}

Because most of the work - that is, action and interaction among the phenomena in scientific and technical writing happens within the nominalisation, there is little grammatical use for the verb. Where verbs do occur, they do not usually carry the action, which is rendered static, and therefore uncontestably fixed, within nominalisations. Quite often the verb's role is to set up a relation between processes such as $A$ causes $B$ to happen, where $\mathrm{A}$ and $\mathrm{B}$ are nominals, nominal groups, or nominalisations:

The effective use of these new technologies will be a key determinant of economic competitiveness, as well as military capability: [DFAT: Sentence 15].

In this sentence, the verb is a verb to be. In SFL terms, to be is performing a relational function between the subject and complement, each of which are large nominal groups containing highly compressed nominalisations: The effective use of these new technologies; a key determinant of economic competitiveness, as well as military capability. In technocratic discourse, the relational verb is the most common form of verb after material types (action verbs), as we explain in the findings section below.

By contrast, mental processes (verbs indicating feeling or thinking) are not very common in scientific or technocratic texts. They are more likely to occur in advocacy writing, for example, in texts about conservation. Martin [38] provides a useful illustration of this by analysing two apparently expository texts produced by separate conservation groups that provide information about preserving kangaroos and seals. These texts showed a higher proportion of material (action) and mental verbs than would 
normally be the case in scientific writing. Scientific and technical texts construe their objective and value-free linguistic character, and their persuasive force, by the absence of verbs indicating thought and feeling, or verbs expressing material, dynamic action.

In keeping with its pseudo-scientific nature, then, technocratic discourse contains a large number of relational processes which attribute characteristics and identify a Thing. They also contain abstract-material processes, which are most usually process metaphors, and a lower number of existential processes. For example, in the DFAT document, analysed more fully below, the following instances occurred

\section{Relational Processes}

- Processes that attribute characteristics:

The distinction between the technology-rich and the technology-poor will be sharp: [Sentence19].

- In this sentence, without modality, the author attributes characteristics to particular types of countries. Processes that identify a Thing:

The effective use of these new technologies will be a key determinant of economic competitiveness, as well as military capability: [Sentence 15].

Technology use identifies the "determinant". What is determined is economic competitiveness and military capability. Thus the semantic intent of the sentence, $A$ causes $B$, is achieved through a relational process linking A (effective use of technologies) to an abstract nominal (determinant) by using an adjectival phrase to B (economic competitiveness and military capability).

\section{Abstract material Processes}

It links currency markets more completely and enables financial markets to judge instantly the policy settings and decisions of national governments. [Sentence 11]

The first two processes in this sentence are material, and the third is mental. However, the second process (enables) is an abstract material process that suggests conscious, mental behaviour.

Existential Processes [verbs that say X exists] 
Although there is [abundant evidence that trade liberalisation and an open economy contribute significantly to economic growth and job creation] .... [Sentence 45].

In this sentence portion, a 'truth' (abundant evidence exists) is presented through the use of the existential is. This evidence then presents the contentious proposition, that trade liberalisation and an open economy contribute significantly to economic growth and job creation, no longer as a proposition but as a given. This is achieved because the proposition is embedded in the very large nominal group specified by the existential process: abundant evidence that trade liberalisation and an open economy contribute significantly to economic growth and job creation..., which is construed as an extant, incontrovertible Thing. ${ }^{5}$

\section{Absence of human agency}

The absence of human agency is a feature of technocratic discourse that arises from its technophilia and technological determinism, as well as from naturalising human conceptions about economy and society, while at the same time dehumanising the language. That is, within technocratic discourse, new technology is simply assumed to be positive and inevitable [39; 11, 22; 23, 281-282]. According to technocracy, what is needed is not a decision about technology's efficacy or appropriateness for the needs of humankind; but rather that the technology needs "drivers" who, of course, come from the ranks of technocracy. With the "black box" of technocratic terminologies to propagate these technologies, and their means of control, technocrats determine whether the technology will be used (really not a question given its technocratically ascribed inevitability), and also operate its social levers. As well, technocrats render the politicaleconomic world in "objective" descriptions using the taxonomies of the prevailing orthodoxy. According to technocracy, this objective political-economic universe acts in ways that are determined by immutable and self-evident economic laws of the market [39, $11,12]$. These internationalised notions of political economy are a kind of 'economic imperialism' in which 'idealisations of economic reason' are operationalised to overcome the 'stubbornly resisting sludge' of civil society [40, 69 - 70].

\footnotetext{
${ }^{5}$ In SFL, the clause, trade liberalisation and an open economy contribute significantly to economic growth, is defined as a postmodifying clause. In other words, it defines what sort of evidence it is that exists.
} 
Linguistically, people can be removed as easily from sentences, just as they are removed from the technological and political-economic models that technocrats use to formulate policies. Ideally, technocracy, as discourse, method, and ideology, adopts values which 'completely leave behind the specifically human world' [Oakeshott, in 12,88 ]. What the science of economics requires, according to Oakeshott, a conservative proponent of a neo-classical economic technocracy, is complete separation from a 'vocabulary which suggests this [human] world' [in 12, 88].

Linguistic removal of people can happen when agency is unclear, when passive voice is used, and when third person existential processes (especially expletive forms such as There are or It is) are used. However, the most effective method is the agentless passive form. Not surprisingly, technocratic texts are often characterised by 'agentless passive clause structures' $[15,60]$ : that is, the absence of specifically human activity. An effective clause needs agency even if it is implicit [35, 168 -169]. Agency is the part of the sentence that makes or causes something to happen. In sentences using relational processes, most common in scientific and technical writing, the agent causes non-human carriers to have attributes [41, 264-265]; for example

$\begin{array}{llll}\text { Lowering interest rates } & \text { Leads to } & \text { share price } & \text { rises. } \\ \text { Agent / Attributor } & \text { Predicate: causative } & \text { Carrier } & \text { Attribute }\end{array}$

Thus, when human agency is removed from a sentence, causation becomes unclear, even impossible to detect. In the sentence share prices in Asia crashed today, no causative agent is evident. When there is agency, it is often in the grammatical subject position:

Fear of a meltdown caused Asian share prices to crash today.

However, they may be elsewhere in the sentence:

The crash in Asian share prices was caused by a fear of a meltdown.

Passive constructions are most evident in clauses using material processes. For example, the active sentence:

The Budget created the conditions necessary for business to flourish.

can also be written as a passive sentence:

The conditions necessary for business to flourish were created by the Budget. 
Thus, an agentless passive clause occurs when the grammatical subject does not perform the action contained in the process/verb and the agent is not to be found anywhere else in the sentence. In the sentence:

Business confidence was adversely affected. the agent affecting business confidence, the doer of the action, is nowhere to be found.

Passive constructions in clauses using relational processes/verbs can be formed where the identifying intensive verb reverses the Token (that which stands for what is being defined) and Value (that which defines) positions. For example, in the following sentence the Token and Value can shift either side of the relational intensive (indicates) without raising too much alarm in the reader:

Globalisation $<$ Token $>$ causes $<$ Verb $>$ increased international trade $<$ Value $>$ OR Increased international trade $<$ Token $>$ causes $<$ Verb $>$ globalisation $<$ Value $>$.

Logically speaking, however, such easily transferred Token and Value positions, especially where issues of causation are concerned, indicate, at best, a tautology or outright mistake; at worst, an effort to confuse and obscure. As the preceding example implies, 'nominalisation puts virtually the entire transitivity system of English' at the disposal of the author [42]. That is to say, once abstracted and abridged by nominalisation, a part of language can play the role of Process, Participant, or Circumstance.

Human agency may also be obscured by using third person forms of agency [15, 60]. Because "no "I" speaks to a "you", no space for dialogue, disagreement or differing points of view is opened up. Even the solidary (inclusive) "we" is absent, and only the authoritative authorial (exclusive) "we" of multiple authorship is allowed' (p. 60).

By using passive constructions, multiple-exclusive authorship, and nominalisation, the technocratic author may make statements in which little or no human activity is evident, and in which agency (who / what does the action) is diffused or completely obscured.

\section{Semantic circularity}

When Marcuse claims that technocratic speech 'moves in synonyms and tautologies ... it never moves toward the qualitative difference' $[16,80]$, he identifies a crucial element of technological language and reasoning. The form of reasoning that underpins the most widely propagated descriptions of globalisation is semantic circularity: 
that is, a statement appears to be true, but may be logically nonsensical. This is because the pseudo-scientific categories upon which technocratic tautologies rest are categories created such that the definition determines the categorisation of the phenomenon (see ITF above): that is, the definition of a Thing contains, at least in part, the phenomenon being described. In other words, we allocate $\mathrm{X}$ to category $\mathrm{Y}$ because it displays $\mathrm{Y}$ characteristics. We can then say that $\mathrm{X}$ will display $\mathrm{Y}$ characteristics because it is in the $\mathrm{Y}$ category. Thus, it is a closed circle of reasoning by virtue of the classificatory process and enables 'expert', self-evident claims to be made about outcomes when phenomena interact. The technocrat's circular dupe is to represent contestable premises as axiomatic, and, therefore, as uncontestable.

The crucial role of categorisation and the expert 'knowledge' thus becomes evident. These areas - the social scientific disciplines and their associated professions - are most insulated from public inspection because of their arbitrary methods of classifying the phenomena which they purport to study. This is the engine room of ideology masquerading as objective social science.

\section{Construing the impossible: The discourse of globalisation in action}

Because it is such an excellent example of technocratic discourse, we have selected a section from chapter two of In The National Interest [7] entitled Globalisation and the Communications Revolution to demonstrate our analytical method. The purpose of the four-page, 50 paragraph, 900 word section is, apparently, to explain globalisation and the communications revolution, and their combined effects on foreign and trade policy for Australia over the coming fifteen years [7, 18-21]. Because the passage is so confusing, we provide a translation of each DFAT sentences, using 'congruent structure'; the way in which meanings are typically realised in everyday, 'concrete language' [42]. Our congruent translations are marked in italics. Following each concrete translation is an assessment using aspects of the analytical tools we outline above.

Sentence 1 Globalisation has characterised the latter part of the twentieth century and will continue into the twenty-first

Globalisation is a defining feature of the latter part of the $20^{\text {th }}$ century. Globalisation will continue into the $21^{\text {st }}$ century.

The condensed nominal globalisation is presented, through the process has characterised, as an attribute of the present time that will continue into the future. No definitions or premises for these truth claims seem to be considered necessary by the 
technocratic author. Remarkably, the nominalisation controls two different Processes (verbs) associated with it; one relational [has characterised], and one existential [will continue]. The effect of this is to cast globalisation in two roles: as a characterising attribute and a continuing process in and of itself.

Sentence 2 A defining feature of globalisation is the way in which business operates: firms increasingly organise their activities on a global scale, forming production chains, including services inputs, that cross many countries and greatly increase global flows of trade and investment.

The way that business operates largely defines globalisation. Because businesses operate internationally, an increased amount of international trade results.

This sentence attempts a partial definition of globalisation. Its logical effect is to create a tautology and a circularity. In effect, it says that because businesses operate globally, globalisation is defined by [businesses operating globally], which, in turn, results in more international activity by businesses, which, of course, defines globalisation. Crucially, both cause and response to the phenomenon created by the cause are conflated in the four items listed. It should be noted that, within the DFAT text, the condensed concept of globalisation from here is now as unpacked as it will be for the reader after this circular definition.

Sentence 3 Globalisation is not new, nor is it just an economic phenomenon: it has important political and social dimensions

Globalisation is not a new phenomenon. It involves economics, politics, and society.

This sentence describes the extent to which globalisation affects Australia. In essence, it says that globalisation affects all fields of policy, and every aspect of Australian society: political, economic, and social. Furthermore, it has done so for some unspecified amount of time. The author gives no reasons for her or his assertions here.

Sentence 4 It is driven by many factors, of which technology, the related mobility of people, goods and ideas, and a liberal trading environment are perhaps the most important.

The four main things propelling globalisation are technology, the related mobility of people, goods and ideas, and unrestricted trade.

This sentence contains the process metaphor is driven by which is functions relational (causative-meronymy: is caused by) but appears as a material process (action verb) in the passive voice. The co-meronymous elements that compose the driving factors are technology, the related mobility of people, goods and ideas, and a liberal trading environment. Each of these co-meronymous nominals is devoid of human agency. The primary noun in the nominal group, mobility of people, is mobility, while of people 
functions as an modifying phrase that converts the potentially human into an economic abstraction.

Within the sentence, it is assumed that technology, in general, affects the mobility of people. That is not necessarily the case [43;39]. Goods and ideas - examples of which might be, respectively, golf balls and daydreams - are also condensed into a single factor identified as a main motivating actor that drives globalisation. No explanation is offered as to why this might be the case. Trade liberalisation, the process by which a liberal trading environment is created through deregulation, is also named as a driving factor of globalisation, again with no logical cause evident. However, this apparent axiom is highly contestable. In fact the reverse is more likely to be the case $[39 ; 43 ; 44 ; 45]$. Much more could be said about the ideological underpinnings of sentence 4, but these become more obvious as DFAT's exposition of globalisation continues.

Sentence 5 The increasingly global activity of firms has implications for trade and policy.

Because businesses operate internationally, trade and policy will be affected.

The circular nature of technocratic discourse is clearly evident in this sentence.

Previously, we are told that globalisation is defined by business trading internationally which, in turn, creates increased international trade. However, this sentence sets the reader up for the ideological component that is to follow by making one of the "implications" of business activity policy. Apart from this rhetorical strategy, the sentence is semantically redundant. The thing that implies effects upon trade and policy (implications) is an abstract, nominalised process that contains an essential part of its own definition: the increasingly global activity of firms has implications for trade [translated: international trade has implications for trade]. The use of the attributive/relational process (the only process in the sentence is has) and an abstract nominalisation (implications) also marks this as a typically technocratic text.

Sentence 6 It reinforces the importance of open markets and focuses attention on national regulatory structures as potential obstacles to the efficient allocation of resources through international trade and investment :...

The global activity of firms reinforces the importance of open markets. It also draws attention to national regulatory structures. These are potential obstacles to international trade and investment. If left unfettered, international trade and investment allocate resources efficiently.

We were set up for this ideological conclusion in the previous sentence; now here it is. The policy that we encounter is plainly consistent with neo-classic market theory, the ideological underpinnings of Australian governments and international policy proponents 
since the mid-1980s $[46,56 ; 39,11]$. The anaphoric nominals (globalisation, liberal trading environment, global activity, trade, policy) are conflated into the pronoun It in the theme position of the sentence. This makes the sentence ambiguous. If the antecedent nominal is assumed to be liberal trading environment, then the sentence is entirely circular. If it is any of the other nominals, globalisation, global activity, trade, or policy, then each is being treated as co-meronymous, thereby re-defining the constituent elements of the text in a way that closes out other possibilities (such as semi-liberal trade or local activity). In either case, given the preceding attempts at defining globalistion, the whole thing is, by this stage, utterly nonsensical from a logical perspective.

Having now closed off the debate to allow the neo-classical ITF to continue on its own terms, the text provides us with four uncontestable propositions, as our congruent translation indicates. The 29 word sentence manages its feat of lexical intimidation by using only two material processes (reinforces, focuses). These two processes relate three complex, highly-compressed, nominal groups that collapse highly-ideological concepts, themes, and processes. In the first statement of 'fact', the sentence proposes that, because firms operate within an international trading environment, open markets are important. This begs the question: to whom are they important and why? Secondly, the global activity of firms focuses attention (a material process performing as a behavioural, personifying verb that suggests an attentive, cognitive entity) on national regulatory structures. There is no human agency here, yet, clearly, the sentence conveys the highly ideological proposition that national regulatory structures are a hindrance to international trade. This is where the ideological proposition is converted into policy imperatives. Yet it has all been done ex cathedra, and without a human being in sight, because it rests upon the "given" that unregulated trade and investment allocates resources efficiently. Such a proposition is clearly contentious. For example, as a direct result of international trade deregulation, 'a new form of highway robbery' [Keegan, 1998, in 43], the richest 358 people in the world now own more than the poorest 2.3 billion people [43]. Inequality of wealth redistribution, world-wide, is rising logarithmically [11].

In the remaining forty-one sentences the text becomes no clearer, nor any less circular. Consequently, it fails, with exquisitely up-to-date sophistication, to explain globalisation and its effects on Australian society. 


\section{Results of the lexico-grammatical analysis}

The results of the micro-analysis of the six sentences of DFAT's text show how the lexico-grammatical and semantic features of technocratic discourse work. In the following section, we present the results of our analysis of the DFAT text as a textual exemplar of technocratic discourse. The results are presented under the five main discursive features that we have identified:

\section{Use of the nominal and the nominal group}

The text is lexically dense because of the role of nominals or nominal groups in technocratic discourse. In its 900 words, the text contains 145 nominals and nominal groups that use 591 words: a mean average of 4.1 words per nominal. In sentence 9 , for example, a 91-word sentence contains 12 nominal groups in the following order: a massive increase in international financial flows; the rate of growth of international trade; the services sector; 27 per cent of world trade; 21 per cent; the growth of transnational corporations; 30 percent of world trade; intra-firm trade; the increasing ease of business travel and the international movement of labour; increases in foreign direct investment flows; the last ten years. These are connected by three passive verbs and one verbal group. The longest nominal group is 12 words in length: national regulatory structures as potential obstacles to the efficient allocation of resources. Of the nominals, only eleven are single-word nominalisations: Globalisation (5 times), technology, firms, attention, interdependence, and implications (2 times). The rest of the nominals are groups. This feature of technocratic discourse closely resembles scientific and technical writing.

\section{Mantric Words}

The most obviously active nominals in the text, that is, those that are allowed to engage in material processes within congruently structured sentences, are, predictably, globalisation, communication technology, financial markets, and trade liberalisation. This can be seen in the following sentences:

\footnotetext{
Technological change facilitates the spread of ideas [Sentence 27]; and

... global communications and global markets bring the world closer together, reinforcing interdependence [Sentence 25].
} 


\section{Limited use of verbs}

Because the DFAT text relies mostly on nominals and nominal groups, there are only 79 finite verbs in 900 words of text. The finite verbal component is 115 words (or $12.7 \%$ of the words in the text). The largest process type is the material group ( $\mathrm{n}=32$; 40.5\%). Although material verbs involve action, most of these are abstract material verbs such as increase, reinforces, compared and process metaphors such as is driven, focuses and have grown. Many of these processes involve causation: make[s] (4 times); caused (2 times); bring[s], meaning to bring about (2 times); lead, has led; engenders, contribute, drive, creates. Because these causative material processes do the work of revealing how mechanisms operate, they provide crucial information about the actual operations of a phenomenon.

The next largest process group is the relational $(n=29 ; 36.7 \%)$. Relational verbs set up a relation between two entities where something is said to be something else. The relation may also be attributive [Q is an attribute of $\mathrm{P}$; or $\mathrm{P}$ has $\mathrm{Q}$ attributes] or identifying [Q is the identity of $\mathrm{P}][35,128$ - 130]. Eighteen of these relational processes are attributive, mostly appearing as the verb to be, although one occurs in the form has characterised and one occurs as has. The ten identification relationals are mostly in the form of the verb to be, although one occurs as are to remain and one as may become. The nine existential verbs (11.4\% of processes, are mostly forms of to be, although four, will continue, is emerging, means, and has are not in this form. Existential verbs assert the existence of something.

Although mental processes occur only six times (7.6\%) in the text, their usage bears close consideration. One type of usage involves judgment, which is presented as disembodied objectivity:

This is reflected in part in a massive increase in international financial flows; the rate of growth of international trade, especially in the services sector, which is expected to account for 27 per cent of world trade by 2010 compared with 21 per cent now .... [Paragraph 39]

or where the judgment is made by an abstract Thing, in fact an abstract authority, not people

Not only are national policy settings judged by the international marketplace, individual companies -irrespective of whether they are exporters-are increasingly subject to the disciplines of international best_practice. [Paragraph 43] 
Mental processes are also used to denote perception, but in both cases where it is used in this way, it is used to state a mis-perception which is about to be corrected by the voice of authority:

Some see it challenging economic sovereignty. In developed economies there is already a growing sense of resistance to what is perceived as the ceaseless demands of the market for restructuring and cost-cutting. . [Paragraph 47]

This exemplifies the claim we made earlier in this paper, that incorrect, oppositional discourses are cast as a mistaken "common sense" idea that is supposed to defer to the more intelligent technocratic understanding. Where the verbal processes

(communicate $[d]$; explained) are used, the text indicates that the problem of globalisation is not so much to do with it as a political-economic phenomenon as a phenomenon that needs to be 'sold' to the polity through better communication.

\section{Absence of human agency:}

The DFAT text contains no human agency whatsoever. While people are mentioned, they are rendered as part of a nominal group as we describe above. The two nominal groups in the text that contain references to humans are: the related mobility of people; the increasing ease of business travel and the international movement of labour. Here, people merely characterise the nature of a particular type of global mobility.

\section{Semantically circular}

DFAT's explanation of globalisation is entirely circular. In fact, globalisation, as an active agent, and a characterising attribute, takes on sixteen different roles within the text. Upon closer inspection, globalisation looks more like a god of some sort than a scientific phenomenon. According to DFAT, globalisation is a multi-dimensional thing; a process; a state of historically specific "being" without a beginning or an end; an autonomous, active, phenomenologically extant agent with a specific speed and trajectory that is affected by the quality of communication, and which directly creates the fate of persons

It creates winners and losers: [Sentence 39].

For some, DFAT say, globalisation is as an observable threat to economic well being. But while globalisation is problematic, it is manageable. Globalisation is presented as a powerful force that DFAT assumes is both inevitable and desirable. However, when viewed as an abstract, phenomenologically evidenced (though not apparent as an 
embodied entity), immutable, active, disciplining, ultimately beneficial agent without a temporal beginning or end that dictates matters of policy (rules and disciplines which must be obeyed); that determines the fate of persons (creates winners and losers); that (both potentially and implicitly) has the power to destroy national economies (whole countries); that should be feared, and which demands continual reform (repentance/correctional treatment); globalisation clearly takes on the characteristics of a God.

The intermediaries between this immutable God, and the fate of the nation state (Australia, in this instance), are business, their goods and ideas, technology, the mobility of people, and, most importantly, trade liberalisation:

Trade liberalisation, far from being part of the problem, is very much a part of the solution: [Sentence 50].

According to DFAT, thanks largely to 'trade liberalisation', Australia has been spared the worst problems that globalisation appears to cause, but of course cannot, because globalisation is intrinsically beneficial. However, DFAT tells us, things will get worse if trade liberalisation is not continually pursued as a matter of policy. Thus, according to DFAT, 'trade liberalisation', which drives 'globalisation', must be pursued if we are to avoid the worst effects of globalisation, which, in turn, is driven by 'trade liberalisation', and so it goes, in an , intractable circle of tautologous logic. Of course, globalisation remains undefined by DFAT, it merely is, was, and will be, so people just might as well get used to it.

\section{Conclusions}

We have argued, and demonstrated, that technocratic discourse is exclusionary and 'monologic' insofar as it is an "expert" language that operates within 'sacrosanct, impenetrable boundaries [and thus]... retards and freezes thought' $[47,133]$. To date technocratic discourse has been a successful tool to "sell" neoclassical social policy, similar to a massive global advertising campaign. Its mantras now infuse "everyday" life as axioms for rationalising seemingly inevitable social and economic policy choices: it just "has to be that way". As a 'jargon of authenticity', technocratic language has become 'a trademark of societalized chosenness, noble and homey at once' [18, 5-6]. In other words, it successfully combines the democratic-familiar with the exclusionarytechnocratic through mass-mediated, repetitive normativity. 
We have shown how this is manifested in specific lexico-grammatical forms, and in semantic circularity. The discourse operates by incorporating highly contestable neoclassical and neo-liberal assumptions as foundational axioms, and by reifying nominalised abstractions that construe the world in particular ways that make it seem pointless to challenge. In technocratic discourse, human agency is virtually non-existent beyond complying with the demands of the 'new world order' [48].

We argue that the emergence of technocratic discourse is politically significant because it advances the interests, to the point of hegemony, of economically dominant countries, transnational corporations, and supranational legislative bodies. By abridging and compressing meaning, technocratic discourse closes other possible meanings of the phenomenon being discussed, engendering a type of 'conformism which is a facet of technological rationality translated into social behaviour' [16, 77]. Of course, a technological rationale for action of any sort

is the result not of a law of movement in technology as such but of its function in today's economy. The need which might resist central control has already been suppressed by the control of the individual consciousness $[19,121]$.

The effect of this closed, yet mantric technocratic discourse is social passivity characterised by a feeling that one can only conform to overwhelming and immutable forces: '[i]nstead of giving [people] a new sense of power, the explanation gives comfort to passivity - particularly public passivity - faced with reigning ideologies' [12, 54 - 55].

The question we have not attempted to answer in this paper is how the technocratic discourse of globalisation in particular is so effectively propagated. From an informed perspective however, it seems clear that those discourse communities which, by necessity, must directly engage with technocracy must do so within the limited discursive possibilities available within the discourse we have described. Those having to do so include, most notably, the media; non-government organisations (NGOs) who perform social and environmental functions in cooperation with government agencies; and businesses. By entering into the technocrats' discursive realm, participants are required to "understand" - or at least appear to understand - technocratic language and reasoning. In this way, technocratic discourse is propagated through and by these organisations. In adopting the mantric formulas, the political axioms remain immutable, quarantined from other infecting discourses with different world views and different ethical orientations. 
The next set of questions we need to ask are : To what degree does the media engage in, propagate, and use technocratic language?; To what degree do NGOs engage in and propagate technocratic rationality and language? How do such engagements perpetuate and increase the social control of technocratic discourse? These questions are of critical importance to social, political, and communication theory and practice and we hope to encourage such studies with this paper.

\section{IEEE References}

1. M.A.K. Halliday, \& J.R. Martin, Writing Science: Literacy and Discursive Power, Falmer Press, London, 1993.

2. J.R. Martin, Literacy In Science: Learning To Handle Text As Technology, in Writing Science: Literacy And Discursive Power, M.A.K. Halliday \& J.R. Martin, 166-202, Falmer Press, London, 1993.

3. B. Russell, On Denoting, in R. C. Marsh (ed.), Logic and Knowledge: Essays 1901-1905, 41-56, London, Unwin Hyman, 1905.

4. P. Graham, (in press), Hypercapitalism: A Political Economy Of Informational Idealism, New Media and Society, 2 (2), 2000.

5. B. McKenna, How Labor Lost Its Labour: The Appropriation And Colonisation Of Labourist Discourse In The Hawke-Keating Years, [Unpublished PhD thesis]. University of Queensland, St. Lucia, 1999.

6. Education Queensland, The Next Decade: A Discussion About The Future Of Queensland State Schools, Education Queensland, Brisbane, Australia, 1999.

7. Department of Foreign Affairs and Trade (DFAT), In The National Interest, Commonwealth of Australia, Canberra, 1997.

8. OECD, 1999 [see other attachment ... Anatomy of a long boom]

9. J. Mintz, The role of allocation in a globalized corporate income tax, [Working paper], New York, International Monetary Fund, 1998.

10. R. Ruggiero, Charting the trade routes of the future. [On-line speech], New York: World Trade Organisation, September 29, 1997. http://www.wto.org/wto/speeches/sanfran1.htm 
11. P. Graham, Critical Systems Theory: A Political Economy of Language, Thought, and Technology. Communication Research, 26:4, 482-507, 1999.

12. J.R. Saul, The Unconscious Civilisation, Penguin, Ringwood Vic, 1997.

13. T. Bewes, Cynicism And Postmodernity, Verso, London, 1997.

14. J. Meynaud, Technocracy, Paul Barnes (trans.), Faber, London, 1968.

15. J.L. Lemke, Textual Politics: Discourse and Social Dynamics, Taylor and Francis, London, 1995.

16. H. Marcuse, One Dimensional Man, Sphere Books, London, 1968.

17. J. Rifkin, The End Of Work: The Decline Of The Global Labor Force And The Dawn Of The Post-Market Era, Putnam, New York, 1995.

18. T.W. Adorno, The Jargon Of Authenticity (K. Tarnowski \& F. Will, Trans), Routledge \& Kegan Paul, London, 1973.

19. M. Horkheimer \& T.W. Adorno, The Dialectic Of Enlightenment, J. Cumming (trans.). Continuum, New York, 1944/1998.

20. H. Caldicott, Why We Should Be Wary of the WTO's Mantra of Globalisation, Sydney Morning Herald, January 5, 2000, p.13, 2000.

21. J.F. Henry, (1999), Property Rights, Markets And Economic Theory: Keynes Versus Neoclassicism - Again. Review of Political Economy, 11:2, 151 - 170, 1999.

22. P. Graham, Widening The Context For Interdisciplinary Social Research: SFL As A Method For Sociology, Anthropology, And Communication Research. Paper delivered at the University of Queensland for the Australian Sytemic Functional Linguistics Association, 1-3 October, 1999, 1999.

23. J.R. Saul, The Doubter's Companion: A Dictionary of Aggressive Common Sense. Penguin, Harmondsworth, 1995. 
24. K.A. Annan,. A Shared Vision Of A Better World, Newsweek: The International Newsmagazine, (December, 1999 - February, 2000), p. 15, 1999.

25. Graham, P. \& McKenna, B. J. (in press). A theoretical and analytical synthesis of autopoiesis and sociolinguistics for the study of organisational communication. Social Semiotics. [Issue 1 2000].

26. M. Slaughter, \& P. Swagel, Does Globalization Lower Wages And Export Jobs? [Economic Issues Paper 11], International Monetary Fund, New York, 1997.

27. Queensland Department of Communication and Information, Local Government and Planning [QDCILGP], Towards A Communication And Information Strategic Plan, Queensland Government, Brisbane, Australia ,1999.

28. W.J. Clinton, (1999, December 17). Memorandum On The Use Of Information Technology To Improve Our Society. Washington, Whitehouse Publications. Available on-line at: http://www.pub.whitehouse.gov/urires/I2R?urn:pdi://oma.eop.gov.us/1999/12/20/2.text.1

29. OECD, Global Information Infrastructure - Global Information Society (GIIGIS): Statement Of Policy Recommendations Made By The ICCP Committee, OECD, Paris, 1996.

30. L. Krauss, The Fifth Essence: The Search For Dark Matter In The Universe, Verso, London, 1989.

31. B. McKenna, How Engineers Write: An Empirical Study Of Engineering Report Writing, Applied Linguistics, 18: 2, 189 - 211, 1997.

32. (Doig \& Wilson, in press)

33. W. Sherden, The Fortune Sellers: The Big Business Of Buying And Selling Predictions, Wiley, New York, 1998. 
34. J.R. Martin, English Text: System And Structure, Benjamins, Amsterdam and Philadelphia, 1992.

35. M.A.K. Halliday, An Introduction To Functional Grammar, Edward Arnold, London, 1994.

36. R. Miller, W. Michalski, \& B. Stevens, The Promises and Perils of $21^{\text {st }}$ Century Technology: An Overview of the Issues (pp. 7-32), in OECD. (1998). $21^{\text {st }}$ century technologies: Promises and perils of a dynamic future, OECD, Paris, 1998.

37. T.W. Adorno, The Culture Industry: Selected Essays On Mass Culture, Routledge, London, 1991.

38. J.R. Martin, Grammaticalising Ecology: The Politics Of Baby Seals And Kangaroos in Language-Semiotics- Ideology, T. Threadgold, E.A. Grosz, G. Kress, \& M.A.K. Halliday (eds.), Association for Studies in Society and Culture, Sydney, 1986.

39. P. Graham, Globalist Fallacies, Fictions, And Facts: The MAI And Neo-Classic Ideology, Australian Rationalist, 46, 15-21, 1998.

40. M. Pusey, Economic Rationalism And The Contest For Civil Society, Thesis Eleven, 44, 69 - 86, 1996.

41. S. Eggins, An Introduction To Systemic Functional Linguistics, Pinter, London, 1994.

42. J.R. Martin, Grace: The Logogenesis Of Freedom, Discourse Studies, 1:1, 29 -56, 1999.

43. Z. Bauman, On Glocalization: Or Globalization For Some, Localization For Others, Thesis Eleven, 54, 37-49, 1998.

43. P. Kennedy, Coming To Terms With Contemporary Capitalism: Beyond The Idealism Of Globalisation And Capitalist Ascendancy Arguments. Sociological Research Online, 3:2. Available online at: http: //www.socioresonline.org.uk/socioresonline/3/2/6.html, 1998. 
44. D. Tetzlaff, Divide And Conquer: Popular Culture And Social Control In Late Capitalism, Media, Culture And Society. 13, 9 -33, 1991.

45. M. Pusey, Economic Rationalism In Canberra: A Nation-Building State Changes Its Mind, Cambridge University Press, Cambridge, 1991.

46. F. Argy, Australia At The Crossroads: Radical Free Market Or A Progressive Liberalism, Allen \& Unwin, Sydney, 1998.

47. M.M. Bakhtin, The Bakhtin Reader: Selected Writings Of Bakhtin, Medvedev, Voloshinov. Pam Morris (ed.), Edwin Arnold, London, 1986.

48. Barker, G. (1998, January 19). Money, Foreign Investment, And The New World Order. The Australian Financial Review, p. 11, 1998.

49. R. Holub, Antonio Gramsci: Beyond Marxism and Postmodernism. London Routledge, London, 1992.

50. J. Hoffman, The Gramscian Challenge: Coercion And Consent In Marxist Political Theory, Basil Blackwell, New York, 1984.

51. P. Bourdieu, Language and Symbolic Power, John B. Thompson (ed.): G. Raymond \& M. Adamson, (trans.), Polity Press, Cambridge UK, 1991.

52. A. Balls, (1999, July 12). Information Revolution Risks Further Dividing Rich And Poor, Financial Times International [UK], p. 4. 